\title{
Comparative Study of Iron (III) Removal Using Charred Sugarcane Bagasse and Precipitating Agent Calcium Hydroxide
}

\author{
Puspa lal Homagai* and Sujan Poudel \\ Amrit Campus, Tribhuvan University, Thamel, Kathmandu, Nepal \\ Email: homagaipl@gmail.com
}

\begin{abstract}
Comparative study of $\mathrm{Fe}(\mathrm{III})$ removal using charred sugarcane bagasse and precipitating reagent calcium hydroxide $\mathrm{Ca}(\mathrm{OH})_{2}$ is presented. The effect of $\mathrm{pH}$, initial metal ion concentration and contact time on the removal of iron were investigated. The optimum $\mathrm{pH}$ for the charred sugarcane bagasse (CSB) and the precipitant calcium hydroxide was found to be 2.5 and 3, respectively. The maximum adsorption capacity for the removal of Fe(III) was found to be $30 \mathrm{mg} / \mathrm{g}$ and $20 \mathrm{mg} / \mathrm{g}$ using CSB and the precipitating capacity of $\mathrm{Ca}(\mathrm{OH})_{2}$, respectively. The equilibrium time has been achieved in 50 minutes and follow pseudo second order kinetics. The experimental data were well fitted with Langmuir adsorption isotherm model.
\end{abstract}

Keywords: Bio adsorption, Fe(III), calcium hydroxide, charred sugarcane bagasse, isotherm

\section{Introduction}

Environment pollution by toxic metals remains a serious problem that has been focus of attention all over the world ${ }^{1}$. Contamination of water, soil, air with hazardous and toxic chemicals plays significant problems for human health and the environment. Metals are toxic pollutants that are not biodegradable, undergo transformation, and have great environmental, public health, and economic impacts ${ }^{2}$. The different forms of elements presence in the nature create a great problem. Some of the elements such as iron $^{3}$, arsenic ${ }^{4}$, manganese ${ }^{5}$, and chromium ${ }^{6}$ are mainly present in natural water as two oxidation states. For instance, $\mathrm{Cr}(\mathrm{VI}), \mathrm{As}(\mathrm{III})$, and $\mathrm{As}(\mathrm{V})$ are known carcinogens, while Fe(II), Fe(III), Mn(II), Mn(VII) and $\mathrm{Cr}(\mathrm{III})$ are essential micronutrients for organisms and plants. However, they become toxic at higher levels.

Iron is the fourth most abundant element present in a variety of rock and soil minerals both as Fe(II) and $\mathrm{Fe}(\mathrm{III}) . \mathrm{Fe}(\mathrm{II})$ is required for proper transport and storage of oxygen by means of hemoglobin and myoglobin while its oxidized forms, methemoglobin and metmyoglobin, which contain Fe(III), will not bind oxygen ${ }^{7}$. Iron plays great role in biological functioning such as in photosynthesis and is the limiting growth nutrient for phytoplankton in some part of the ocean ${ }^{8}$. Both $\mathrm{Fe}$ (II) and $\mathrm{Fe}$ (III) are important in the biosphere, serving as an active centre of a wide range of proteins such as oxidases and reductases. Water effluents from steel tempering, coal coking and mining industries for examples, contain significant quantities of iron, nickel, copper and zinc $^{9-11}$. The application of low-cost adsorbents obtained from agricultural byproduct widely used in the recent research as a replacement for costly conventional

\footnotetext{
* Corresponding author
} 


\section{J. Nepal Chem. Soc., Vol. 36, 2017}

methods of removal heavy metal ions from waste water ${ }^{12-15}$. Due to the advantages of economic feasibility and environmental friendly behavior, adsorption is regarded as the best technique for removing heavy metal ions at trace levels ${ }^{16-19}$.

The objective of this study is to develop low-cost adsorbent from sugarcane bagasse modified by chemical treatments for the effective removal of Fe(III) ions from contaminated water. The FTIR characterization indicates that the chemically modified sugarcane has the functional groups like phenols, carboxylic acids, lactones, hydroxides etc. on the surface of adsorbent to change and increase the surface area. The adsorption capacity was greatly influenced by surface group changes.

\section{Experimental}

\section{Preparation of Adsorbent}

Locally collected sugarcane bagasse was dried and grounded using mechanical grinder which is known as raw sugarcane bagasse. Then the raw sugarcane bagasse was treated with concentrated $\mathrm{H}_{2} \mathrm{SO}_{4}$ in $1: 2(\mathrm{w} / \mathrm{v})$. It was washed till neutrality finally dried at $70{ }^{\circ} \mathrm{C}$ and stored after keeping in desiccator and the sample is called charred sugarcane bagasse(CSB).

\section{Chemicals}

Chemicals and reagents used in the experiment were analytical grade. Exact $1000 \mathrm{ppm}$ stock solution was prepared by dissolving 2.158 gram of salt $\mathrm{NH}_{4} \mathrm{Fe}\left(\mathrm{SO}_{4}\right)_{2} \cdot 12 \mathrm{H}_{2} \mathrm{O}$ in $250 \mathrm{~mL}$ volumetric flask. Likewise, the solution of $1 \mathrm{M} \mathrm{HNO}_{3}, 0.1 \mathrm{M} \mathrm{NaOH}, 1 \mathrm{M} \mathrm{HCl}, 0.1 \mathrm{M} \mathrm{Ca}(\mathrm{OH})_{2}, \mathrm{KSCN}$ solution were prepared by adding calculated mass of the requirement.

\section{Adsorption Experiments}

The $\mathrm{pH}$ of the working solution of $\mathrm{Fe}(\mathrm{III})$ was adjusted by adding either small amount of $\mathrm{HCl}$ or $\mathrm{NaOH}$ after adding $0.1 \mathrm{M}$ of HEPES as a buffering agent. The flasks were shaken at a speed of $180 \mathrm{rpm}$ in the mechanical shaker. The initial and equilibrium concentration of the metal ions were measured using spectrophotometer. The removal efficiency, $\mathrm{A} \%$ of the metal ion was calculated from eq. (1)

$$
A \%=\frac{C_{l}-C_{e}}{C_{e}} \times 100
$$

The sorption capacity of metal ions is the concentration of the metal ions on the adsorbent and can be calculated based on the mass balance principle using equation (2).

$$
q=\frac{c_{l-} \epsilon_{e}}{c_{e}} \times \frac{L}{1000}
$$

In above equations, $q$ represents the amount of metal uptake per unit mass of the adsorbent $\left(\mathrm{mg} \mathrm{g}^{-1}\right), \mathrm{L}$ is the volume of the test solution $(\mathrm{mL}), \mathrm{W}$ is the dry mass of the adsorbent $(\mathrm{g}), C_{i}$ and $C_{e}$ the initial and final concentrations $\left(\mathrm{mg} \mathrm{dm}^{-3}\right)$, respectively.

\section{Results and Discussion}

\section{FTIR Analysis}

The chemical structure of the adsorbent is of vital importance in understanding the adsorption process. FTIR technique is an important tool to identify the characteristic functional groups, which are involved in adsorption of metal ions. FTIR analysis was performed in this study to investigate the surface functional 
groups of charred sugarcane bagasse before and after the adsorption of Fe (III) metal ions. The peaks range shows the functional group present in the test sample.

In this transformation, many characteristics bands are shifted at the maximum peaks and absorbance is changed. The peak observed at $3402.43 \mathrm{~cm}^{-1}$ is due to stretching vibration of the $\mathrm{O}-\mathrm{H}$ groups. Although there is possibility of overlapping between the $\mathrm{N}-\mathrm{H}$ and the $\mathrm{O}-\mathrm{H}$ stretching vibrations, the strong broad band at the wave number region number of 3248.13 to $3541.31 \mathrm{~cm}^{-1}$ is characteristic of the NH stretching vibration the range 1141.86 to $1674.21 \mathrm{~cm}^{-1}$ are closely related to the $\mathrm{NH}$ binding, $\mathrm{C}-\mathrm{N}$ stretching, and $\mathrm{N}-\mathrm{H}$ rocking bands. The range 326356 to $3363.86 \mathrm{~cm}^{-1}$ may be due to overlapping of O-H and N-H stretching, which is consistent with the peaks at 1644 and $1047 \mathrm{~cm}^{-1}$ assigned to alcoholic C-O and C-N stretching vibrations.

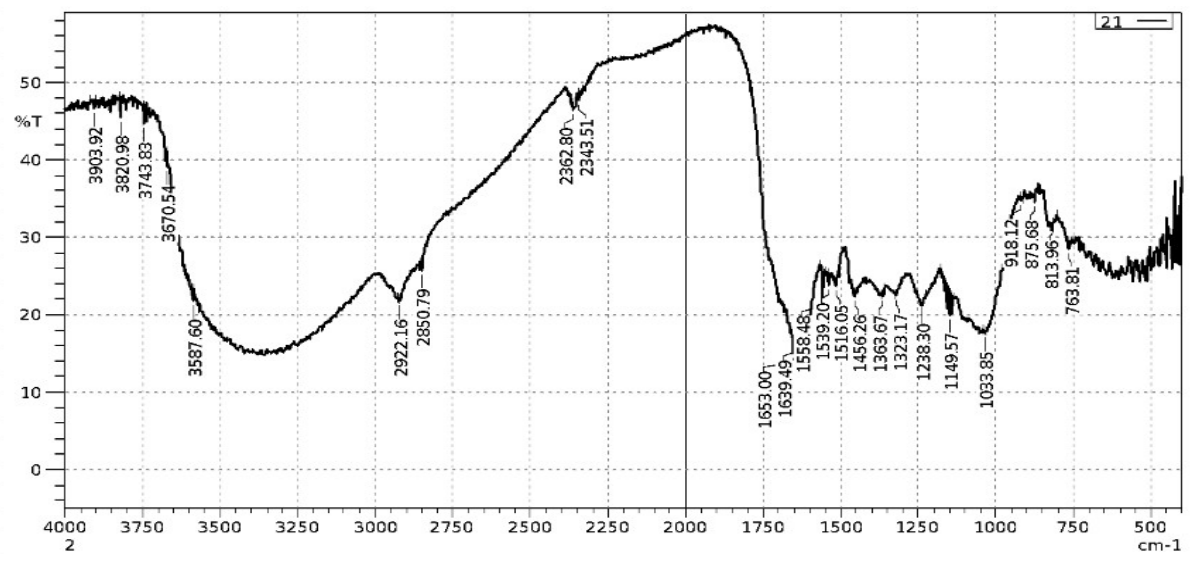

Figure 1: FTIR of charred sugarcane bagasse

\section{Effect of pH}

The $\mathrm{pH}$ of the solution has significant impact on the uptake of Fe (III) ions, since it determines the surface charge of the adsorbent and the degree of ionization of the adsorbate. Fig: 2 show the effect of $\mathrm{pH}$ on adsorption of Fe (III) ions onto CSB at initial concentration of $25 \mathrm{ppm}$ at room temperature. The experiment was carried out to find the effect of $\mathrm{pH}$ for the adsorption of $\mathrm{Fe}$ (III), taking the $\mathrm{pH}$ range of 0.5 to 4.5 . The percentage removal of Fe (III) ions by charred sugarcane bagasse increased from $8.57 \%$ to $84.61 \%$ within the $\mathrm{pH}$ range and maximum adsorption occurs at $\mathrm{pH} 2.5$.

It was found that little sorption of Fe(III) at lower $\mathrm{pH}$ could be ascribed due to the hydrogen ions competing with metal ions for sorption sites. At higher $\mathrm{H}^{+}$concentration, the adsorbent surface becomes positively charged, thus reducing the attraction between adsorbent and metal ions. As $\mathrm{pH}$ increases surface charge of adsorbent become negative and thus facilitating greater metal uptake due to cations exchange mechanism. Maximum adsorption of Fe(III) at higher value of $\mathrm{pH}$ is due to the electrostatic attraction between negative and positive surface function of the adsorbent. The optimum $\mathrm{pH}$ was investigated as 2.5 for $\mathrm{Fe}(\mathrm{III})$ removal onto CSB. 


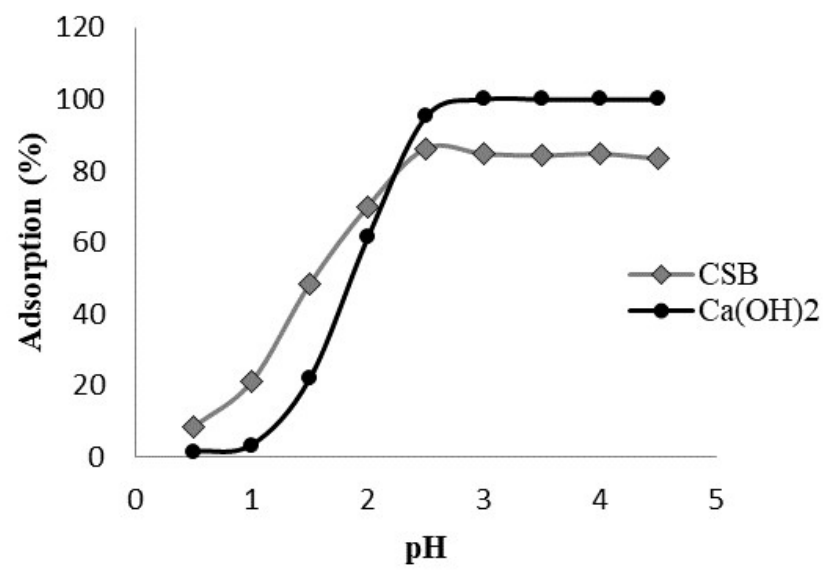

Figure 2: Effect of pH for Adsorption of $\mathrm{Fe}$ (III) onto $\mathrm{CSB}$ and $\mathrm{Ca}(\mathrm{OH})_{2}$

\section{Effect of $\mathrm{pH}$ on Precipitant $\mathrm{Ca}(\mathrm{OH})_{2}$}

Fe (III) ions are weakly acidic and hydrolyze in solution producing a less soluble complex. We know that the solubility of the salt is a function of the $\mathrm{pH}$ and it increases as the $\mathrm{pH}$ decreases. The maximum solubility is found under acidic conditions when the concentrations of the hydrolyze species became negligible. Removal of the heavy metals ions as hydroxide formation is the most common heavy metal precipitation method. The addition of calcium hydroxide is used to raise the $\mathrm{pH}$ for removal of $\mathrm{Fe}(\mathrm{III})$ by precipitating and settling process. Removal of $\mathrm{Fe}(\mathrm{III})$ increase with the increase in $\mathrm{pH}$ and the optimum removal was reached at $\mathrm{pH} 3$.

\section{Adsorption Isotherms}

The surface coverage of adsorbate is a function of adsorption of adsorbents and adsorption isotherm describes the equilibrium of the adsorption of materials at a surface at constant temperature. Here isotherm studies were performed using various concentration of the metal ion ranging from 25 to 1000 $\mathrm{mg} / \mathrm{L}$. For batch adsorption experiment, $25 \mathrm{mg}$ of adsorbent was equilibrated with $25 \mathrm{~mL}$ of synthetic $\mathrm{Fe}(\mathrm{III})$ solution in conical flask for 24 hours to attain equilibrium. All the adsorption data were tested with the Langmuir and Freundlich isotherm model using linear form as represented by equations (3) and (4).

$$
\begin{aligned}
& \frac{C_{\odot}}{q_{\epsilon}}=\frac{C_{\odot}}{q_{m} b}+\frac{C_{\odot}}{q_{m}} \\
& \operatorname{In} q_{\epsilon}=\operatorname{In} K_{f}+\frac{1}{n} \operatorname{In} C_{\odot}
\end{aligned}
$$

Where $C_{e}(\mathrm{mg} / \mathrm{L})$ is the equilibrium concentration of the metal ion in aqueous solution and $q_{e}$ is the amount $\mathrm{Fe}(\mathrm{III})$ adsorbed at equilibrium $(\mathrm{mg} / \mathrm{g})$. The Langmuir constant $q_{m}(\mathrm{mg} / \mathrm{g})$ represents the monolayer adsorption capacity, $\mathrm{b}(\mathrm{L} / \mathrm{mg})$ the binding constant, $\mathrm{n}$ (dimensionless) a constant of adsorption intensity and $K_{f}(L / m g)$ is Freundlich constant characterizing the adsorption capacity. To examine the relationship between the metal sorption capacity $\left(q_{e}\right)$ and the metal ions at equilibrium $\left(C_{e}\right)$, the sorption equilibrium data for Fe(III) was compared to Langmuir and Freundlich isotherm models, where the 
Langmuir and Freundlich constants and its correlation coefficients evaluated from the isotherm for $\mathrm{Fe}^{+++}$ are given in table 1. The sorption characteristics of the metal ions on the charred sugarcane bagasse followed more closely the Langmuir isotherm model than the Freundlich isotherm model. The high value of Langmuir correlation coefficient confirmed that the Langmuir isotherm is the best fitted than Freundlich isotherm onto CSB. The maximum adsorption capacity based on the experimental result is shown in Figure 3 for both charred sugarcane bagasse and calcium hydroxide respectively.

On the other hand, the theoretical maximum monolayer capacity $\left(q_{m}\right)$ of the metal ion based on Langmuir adsorption equation were determined to be $0.454 \mathrm{mg} / \mathrm{g}$ and $0.769 \mathrm{mg} / \mathrm{g}$ from figure 4 for charred sugarcane bagasse and calcium hydroxide. This result is in closed agreement against each other suggesting that iron metal can be quantitatively sequestered on to charred sugarcane bagasse and calcium hydroxide. The essential characteristics and the feasibility of the Langmuir isotherm in terms of a dimensionless constant, separation factor or equilibrium parameters $R_{L}$, which is defined as by equation (5).

$$
R_{L}=\frac{1}{1+b c_{i}}
$$

The $R_{L}$ value indicates the shape of the isotherm as $R_{L}>1$ : unfavorable, $R_{L}=1$ : linear, $0<R_{L}>$ 1: favorable, $R_{L}=0$ : irreversible adsorption. The value of $R_{L}$ found by calculating the data of $\mathrm{b}$, taking initial that concentration of sorbate and concluded that Langmuir adsorption isotherm is favorable.

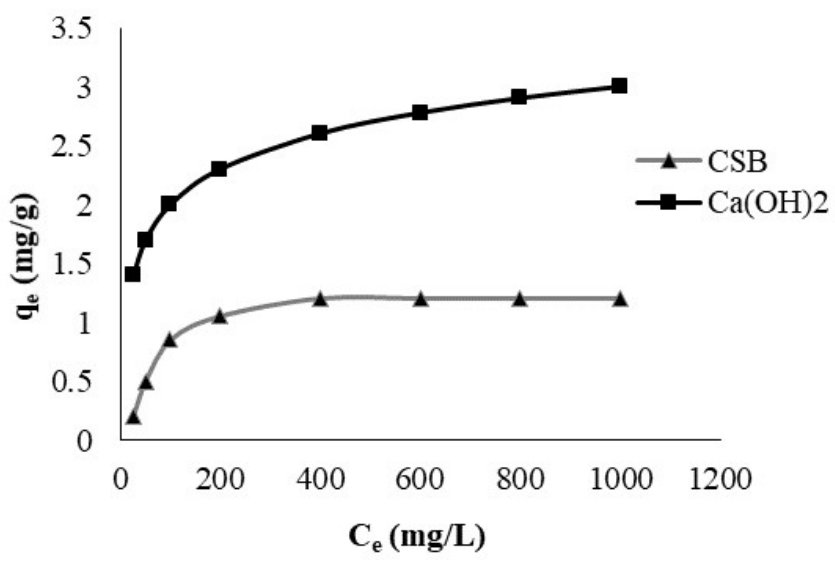

Figure 3: Adsorption isotherm for adsorption of Fe (III) onto CSB and $\mathrm{Ca}(\mathrm{OH})_{2}$ 


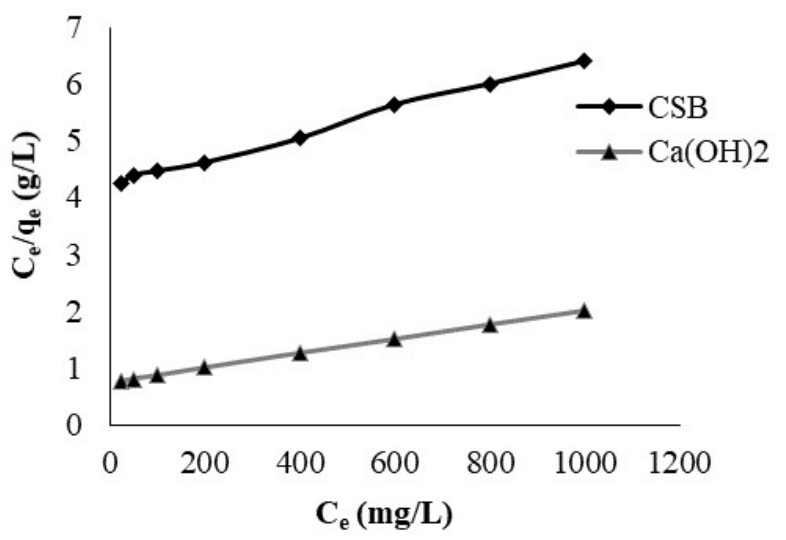

Figure 4: Langmuir Plot for Adsorption of Fe(III) ions onto CSB and $\mathrm{Ca}(\mathrm{OH})_{2}$

Table 1: Langmuir Parameters for Adsorption of Fe(III)

\begin{tabular}{|c|c|c|l|l|l|}
\hline \multirow{2}{*}{ SN } & \multirow{2}{*}{ Adsorbent } & \multirow{2}{*}{ Metal } & \multicolumn{3}{|c|}{ Langmuir isotherm } \\
\cline { 4 - 6 } & & & $\mathrm{q}_{\mathrm{m}}(\mathrm{mg} / \mathrm{g})$ & $\mathrm{b}(\mathrm{L} / \mathrm{mg})$ & $\mathrm{R}^{2}$ \\
\hline 1 & $\mathrm{CSB}$ & $\mathrm{Fe}(\mathrm{III})$ & 20 & 1.0001 & 0.995 \\
\hline 2 & $\mathrm{Ca}(\mathrm{OH})_{2}$ & $\mathrm{Fe}(\mathrm{III})$ & 18 & 0.0017 & 0.999 \\
\hline
\end{tabular}

Adsorption Kinetics

The effect of contact time on the removal of Fe (III) ions from aqueous solution by modified adsobent was. Adsorption kinetics of metal ions were obtained within contact times between 5 to 360 minutes for the removal of $\mathrm{Fe}$ (III) using $\mathrm{CSB}$ and precipitating reagent $\mathrm{Ca}(\mathrm{OH})_{2}$. Adsorption increases with time and finally equilibrium point is attained which are shown in figure 6 and 7. Kinetic studies for the adsorption of Fe (III) was studied using different kinetic models, pseudo first order (Lagergrens 1898) and pseudo second order (Ho, 1995). The pseudo second order kinetic equation ${ }^{20}$ is well fitted used as the following form:

$$
\frac{t}{q_{t}}=\frac{1}{K_{\xi} q_{\varepsilon}^{2}}+\frac{t}{q_{\varepsilon}}
$$

Where $q_{t}(\mathrm{mg} / \mathrm{g})$ is the amount of adsorption at time $\mathrm{t}(\mathrm{min}), K_{2}\left(\mathrm{~g} \mathrm{mg}^{-1} \mathrm{~min}^{-1}\right)$ is the rate constant of the pseudo second order kinetics adsorption. The values of $K_{2}$ and $q_{\odot}$ can be obtained from intercept and slope of the plot and the experimental data can be explained by the pseudo second order kinetic model, with the correlation coefficient $\mathrm{R}^{2}$ being almost unity $(0.99)$ for the $\mathrm{Fe}$ (III) ions. The experimental value of $K_{2}$ was found from the plot that is based on kinetic model as shown in Figure 8. 


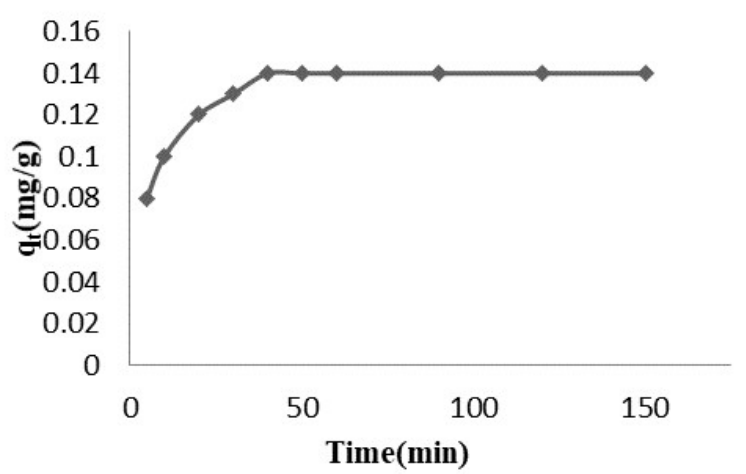

Figure 6: Adsorption Kinetics for Adsorption of Fe(III) onto CSB

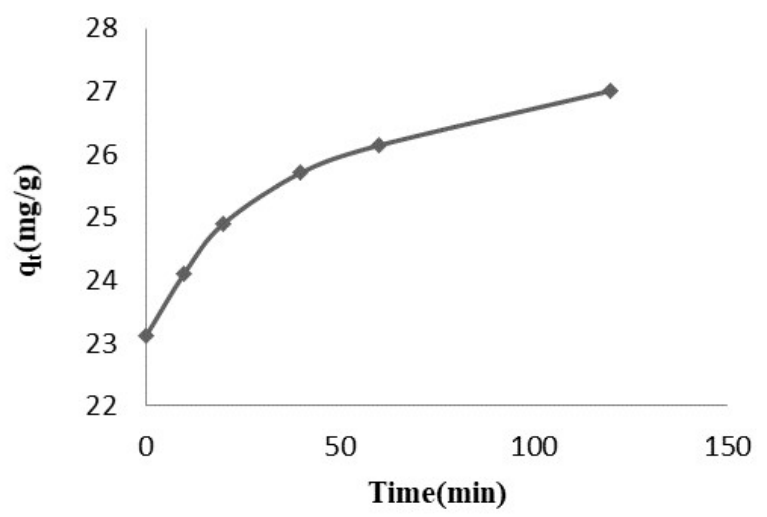

Figure 7: Kinetics for Separation of Fe(III) using $\mathrm{Ca}(\mathrm{OH})_{2}$

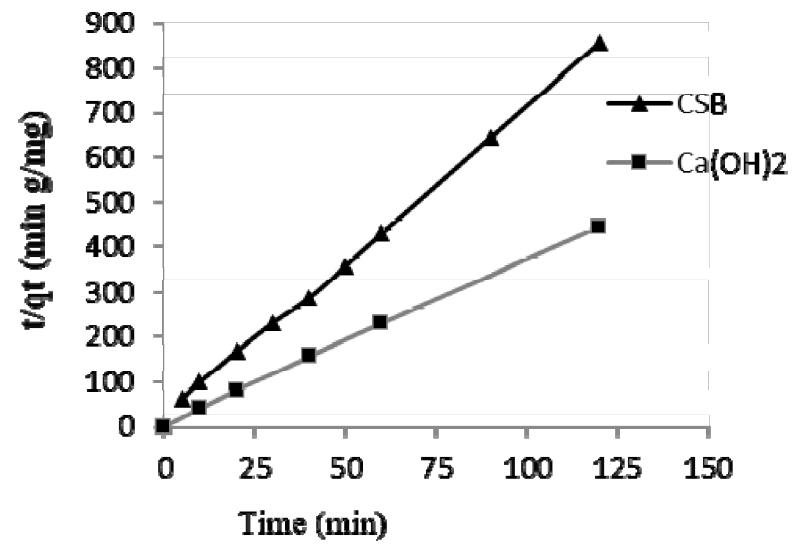

Figure 8: Pseudo Second Order Kinetics for Adsorption of Fe(III) onto CSB and $\mathrm{Ca}(\mathrm{OH})_{2}$ 


\section{J. Nepal Chem. Soc., Vol. 36, 2017}

Pseudo second order plot of (t/qt) versus $t$ gave perfect straight line for the removal of $\mathrm{Fe}(\mathrm{III})$ onto CSB and $\mathrm{Ca}(\mathrm{OH})_{2}$ and it proves that the adsorption reaction follows the pseudo second order kinetics model. The correlation coefficient is 0.99 conform that the adsorption reaction follows pseudo second order model. The value of correlation coefficient and the rate constant for metals and adsorbents are shown in the table. On the increasing the time the precipitating rate was increases with the initial dose $1000 \mathrm{mg} / \mathrm{L}$. the $100 \%$ removal was found at 120 minutes and nearly to 100 at 60 minutes.

\section{Conclusions}

The studies have shown that the charred sugarcane bagasse and inorganic base calcium hydroxide can be used for the removal of Fe(III) from the aqueous solution through adsorption and precipitation. The efficiency of the adsorbent can be increased by chemical modification. The optimum $\mathrm{pH}$ for the adsorption of $\mathrm{Fe}(\mathrm{III})$ onto $\mathrm{CSB}$ is to be found 2.5 and precipitation is completed at $\mathrm{pH} 3$ using precipitant $\mathrm{Ca}(\mathrm{OH})_{2}$. The maximum adsorption $\mathrm{q}_{\mathrm{m}}$ was found $20 \mathrm{mg} / \mathrm{g}$ onto CSB and $\mathrm{q}_{\mathrm{m}} 18 \mathrm{mg} / \mathrm{g}$ was found for $\mathrm{Ca}(\mathrm{OH})_{2}$ and both follow the pseudo second order kinetics. Langmuir adsorption isotherm model was found to be more fitted than Freundlich model. The equilibrium time for the adsorption was found to be 40 minutes for the adsorption of $\mathrm{Fe}(\mathrm{III})$ ions onto $\mathrm{CSB}$ and for complete precipitation required 120 minutes using $\mathrm{Ca}(\mathrm{OH})_{2}$.

Based on this study, it is concluded that modified sugarcane bagasse can be used as low-cost adsorbent for the removal of $\mathrm{Fe}(\mathrm{III})$ and it is superior to the inorganic precipitating agent calcium hydroxide.

\section{Acknowledgement}

The authors are thankful to the Head of the Department of Chemistry, Amrit Campus, Tribhuvan University, Kathmandu, Nepal for providing the available research facilities to conduct this research work.

\section{References}

1. P.L., Homagai, J. Nepal Chem. Soc., 2012, 29, 34.

2. V.K, Gupta, S. Sharma, Environ. Sci. Technol., 2002, 36, 3612.

3. L.Y., Mulaudzi, J.F.V., Staden, R.I. Stefan,. Anal. Chim. Acta., 2002, 46, 35.

4. T., Balaji, H., Matsunaga, Anal. Sci., 2002, 18, 1345.

5. A. Xue, S. Qian, G. Huang, X. Han, Analyst., 2001, 126, 239.

6. A. Xue, S. Qian, G. Huang, L. Chen, J. Anal. At. Spectrom., 2000, 15, 1513.

7. A. Safavi, H. Abdollahi,. J. Microchem., 1999, 63, 211-217.

8. RJ. Kieber, K. Williams, J.D. Willey, S. Skrabal, G.B. Avery Jr., Marine Chem., 2001, 73, 83.

9. Z. Aksu, A. Calik, A.Y. Dursun, Z. Demircan,. Process Biochem., 1999, 34,483.

10. P.L. Homagai, K.N. Ghimire, K. Inoue, Sep. Sc. Technol., 2011, 46, 330.

11. W.W.S. Nagh, M.A.K.M Hanafiah. Technol., 2008, 99, 3935.

12. C.R.T. Tarley, S.L.C. Ferreira, M.A.Z. Arruda, J. Microchem., 2004, 77, 163.

13. R.M. Rowell, F.M. Keany, Fiber boards made from acetylated bagasse fibers. Wood Fiber Sci., 1991, 23, 15

14. I. Ali, V.K. Gupta, Nat. Protoc., 2007, 1 (6), 2661.

15. D. Mohan, K.P. Singh, Water Res., 2002, 36, 2304.

16. D. Mohan, Jr C.U. Pittman, J. Hazard. Mater., 2006, 137, 762.

17. U. Garg, M.P. Kaur, G.K. Jawa, D. Sud, V.K. Garg, J. Hazard. Mater., 2008, 154, 1149.

18. M. Rao, A.V. Parwate, A.G. Bhole, Waste Manage., 2002, 22, 821.

19. E.M. Soliman, S.A. Ahmed, Int. J. Environ. Anal. Chem., 2009, 89, 389.

20. Y.S. Ho, G. McKay, Process Biochem.,1999, 34, 451. 